\title{
A plataforma eduCAPES e sua contribuição para a formação integral: conhecimento e uso das tecnologias digitais por parte dos professores do Ensino Médio Integrado
}

\author{
The eduCAPES platform and is contribution to integral education: \\ knowledge and use of digital technologies by teachers of Integrad High \\ School
}

\author{
Recebido: 02/06/2020 | Revisado: \\ 11/06/2020 | Aceito: 22/07/2020 | \\ Publicado: 16/06/2021 \\ Cyntia Layane Gusmão Souza Sampaio \\ ORCID: http://orcid.org/0000-0001-7919- \\ 2399 \\ Instituto Federal de Educação, Ciência e \\ Tecnologia Baiano (IF Baiano) \\ E-mail: cyntia.souza@ifbaiano.edu.br
}

Claudio Nei Nascimento da Silva ORCID: https://orcid.org/0000-0003-32855268

Instituto Federal de Educação, Ciência e Tecnologia de Brasília

E-mail: claudio.silva@ifb.edu.br

Como citar: SAMPAIO, C. L. G. S.; SILVA, C. N. N.; A plataforma eduCAPES e sua contribuição para a formação integral: conhecimento e uso das tecnologias digitais por parte dos professores do Ensino Médio Integrado. Revista Brasileira da Educação Profissional e Tecnológica, [S.I.], v. 1, n. 20, p. e10314, jun. 2021. ISSN 2447-1801.

This work is licensed under a Creative Commons Attribution 4.0 Unported License.

\begin{abstract}
Resumo
Objetivou identificar o uso da plataforma eduCAPES por parte dos professores do Ensino Médio Integrado enquanto recurso a serviço de um processo de ensino-aprendizagem comprometido com a formação integral dos estudantes. Foram aplicados questionários on-linee entrevistas semiestruturadas, com 151 professores do Instituto Federal Baiano, para a coleta de dados sobre conhecimento e utilização de Objetos de Aprendizagens depositados em plataforma digital. Os resultados evidenciaram um baixo nível de conhecimento em relação à plataforma, como também, revelou algumas dificuldades que os professores enfrentam no uso destas tecnologias. Conclui que o uso de tecnologias é condição para a prática docente em um mundo altamente tecnologizado e que a Plataforma eduCAPES pode representar uma importante contribuição para o incremento do trabalho docente na perspectiva de uma formação integral.
\end{abstract}

Palavras-chave: Plataforma eduCAPES. Novas Tecnologias. Ensino Médio Integrado. Recursos Educacionais Abertos. Objetos de Aprendizagem.

\begin{abstract}
It aimed to identify the use of the eduCAPES platform by the teachers of Integrated High School as a resource in the service of a teaching-learning process committed to the integral training of students. on-linequestionnaires and semistructured interviews were applied with 151 teachers from the Federal Institute of Bahia, to collect data on knowledge and use of Learning Objects deposited on a digital platform. The results showed a low level of knowledge in relation to the platform, but also revealed some difficulties that teachers face in the use of these technologies. It concludes that the use of technologies is a condition for teaching practice in a highly technological world and that the eduCAPES Platform can represent an important contribution to the increase of teaching work in the perspective of comprehensive training
\end{abstract}

Keywords: EduCapes platform. New Technologies. Integrated High School. Open Educational Resources. Learning Objects 


\section{INTRODUÇÃO}

O Ensino Médio Integrado (EMI) pode ser considerado um dos principais instrumentos para a formação humana integral, possibilitando a efetivação de uma educação que caminhe para a formação de cidadãos críticos, comprometidos com a sociedade em sua volta, entendendo que, para alunos diferentes existem práticas pedagógicas diferentes, conforme defendem Araújo e Silva (2017). Assim, diante da complexidade pedagógica que essa formação exige, o apoio tecnológico através dos recursos educacionais disponíveis nas formas de objeto de aprendizagem, repositórios e plataformas institucionais se fazem necessários para que essa realidade possa deixar de ser uma mera utopia.

Nessa perspectiva, conquistar e motivar os alunos nas salas de aulas são tarefas cada vez mais desafiadoras. No atual contexto educacional, manter os alunos conectados às atividades acadêmicas tem sido desafiador, a despeito das longas horas em que os professores passam preparando o conteúdo a ser aplicado. Para que se tornem não só atrativas, mas também capazes de formar cidadãos críticos, é de extrema importância que as aulas sejam incrementadas com recursos tecnológicos inovadores e que promovam a interação entre os alunos.

Neste sentido, identificamos que os programas de mestrado profissional em curso no país produzem um número expressivo de produtos educacionais todos os anos e que podem ser utilizados como estratégia para a melhoria do ensinoaprendizagem. A tendência de disponibilização desses produtos será crescente, principalmente se se considerar a implementação do Mestrado Profissional em Educação Profissional em Rede Nacional (ProfEPT), articulado pelo Conselho Nacional das Instituições da Rede Federal de Educação, Científica e Tecnológica (CONIF) e com o apoio da Secretaria de Educação Profissional e Tecnológica do Ministério da Educação SETEC/MEC. Esse volume expressivo de informação científica e tecnológica gera a necessidade de desenvolvimento de processos de recuperação da informação a partir do caráter da relevância e da pertinência ao Ensino Técnico Integrado, tendo em consideração os pressupostos políticos, filosóficos e pedagógicos subjacentes a este nível de ensino.

Assim, este trabalho é resultado de uma pesquisa que teve como objetivo identificar o uso da plataforma eduCAPES por parte dos professores do Ensino Médio Integrado, enquanto recurso a serviço de um processo de ensino-aprendizagem comprometido com a formação integral dos estudantes. Para isso, estabeleceram-se duas questões principais para as quais este trabalho busca fornecer respostas: a) Qual o grau de conhecimento dos professores sobre os recursos educacionais abertos, objetos de aprendizagem e sobre a plataforma eduCAPES? b) Quais as dificuldades encontradas para a apropriação e utilização da plataforma eduCAPES pelos professores do Ensino Médio Integrado? 


\section{PERCURSO METODOLOGICO}

A pesquisa foi desenvolvida no Instituto Federal de Educação, Ciência e Tecnologia Baiano - IF Baiano -. Para este estudo, foram consideradas duas abordagens amostrais, definidas de acordo com o caráter da pesquisa. Para a abordagem quantitativa, a população-alvo foi constituída por docentes do quadro da instituição e, desta forma, o universo da pesquisa foi composto por 741 professores. Foi realizada uma amostragem por meio de método probabilístico com um número de entrevistados de 151 docentes, considerando para o cálculo do tamanho da amostra o total de docentes da instituição, a margem de erro de $6 \%$ e grau de confiança de $90 \%$, definidos previamente, para garantir que as respostas tivessem uma representatividade em relação ao universo de participantes.

Para a realização de entrevista semiestruturada, ou seja, para a coleta com enfoque qualitativo, foi previsto como pré-requisito o conhecimento total prévio da Plataforma eduCAPES por parte dos docentes. Neste caso, a amostra foi definida por conveniência, sendo composta por três docentes identificados após a análise de dados inicial. Dessa forma, para coleta dos dados foram utilizados dois instrumentos: (i) questionário composto por questões fechadas e abertas; e (ii) entrevista semiestruturada.

O questionário teve como objetivo identificar a compreensão, percepção e uso dos participantes da pesquisa sobre a Plataforma eduCAPES como recurso educativo, inerente a um processo de ensino-aprendizagem, considerando a formação integral do estudante. O questionário foi enviado aos participantes por meio de endereço eletrônico de e-mail, sendo utilizado um formulário eletrônico elaborado a partir de uma nuvem de armazenamento do Google Drive.

Para a entrevista semiestruturada, foram previamente definidas questões que possibilitaram discorrer sobre o tema proposto, focadas em identificar quais competências e habilidades os professores do Ensino Médio Integrado precisam desenvolver para interagir com a plataforma eduCAPES, bem como, quais as dificuldades encontradas em seu uso. A coleta de dados via questionário onlineocorreu entre os meses de novembro e dezembro do ano de 2019. As entrevistas semiestruturadas foram conduzidas nos meses de fevereiro e março do ano de 2020.

Os dados oriundos do questionário eletrônico foram extraídos e tratados inicialmente utilizando-se o software Microsoft Office Exce ${ }^{\circledR}$. Foi gerado um banco de dados e realizadas análises descritivas, por meio de frequências absolutas e relativas, utilizando o software Stata, versão 15.1. O software foi utilizado por se tratar de um pacote completo e integrado, capaz de permitir a manipulação e padrão dos dados, visualização e estimação das estatísticas.

As entrevistas foram transcritas e, em seguida, procedeu-se a uma leitura detalhada e cuidadosa de todo material, a fim de destacar os conteúdos evocados que respondiam de forma mais direta às questões levantadas nos objetivos específicos, analisadas de forma qualitativa. Segundo Lüdke e André (1986, p. 2528), "analisar os dados qualitativos significa "trabalhar" todo o material obtido durante 
a pesquisa, ou seja, os relatos das observações, as transcrições de entrevistas, as análises de documentos e as demais informações disponíveis". Nesse sentido, os dados qualitativos, por possuírem uma riqueza de informações e detalhes, proporcionaram um leque amplo de material para investigação e análise, garantindo o conhecimento crítico da realidade. Por isso, demandam também maior grau de rigor metodológico para ser analisado.

\section{A EDUCAPES E A CONTRIBUIÇÃO DOS MESTRADOS PROFISSIONAIS NA PRODUÇÃO DE RECURSOS EDUCACIONAIS ABERTOS PARA O ENSINO: UMA REVISÃO DE LITERATURA}

A eduCAPES é uma plataforma que armazena objetos educacionais abertos, que podem ser utilizados por alunos e professores da Educação Básica, Superior e pós-graduação na perspectiva de melhorar sua formação (CAPES, 2018). A Diretoria de Educação à Distância da Coordenação de Aperfeiçoamento de Pessoal de Nível Superior - DED/CAPES -, objetivando publicizar, compartilhar e disseminar os materiais educacionais produzidos nos cursos ofertados no âmbito do Sistema Universidade Aberta do Brasil - UAB -, desenvolveu o portal educacional online, nomeado de eduCAPES. Este Portal engloba em seu acervo, milhares de objetos de aprendizagem, incluindo textos, livros didáticos, artigos de pesquisa, teses, dissertações, videoaulas, áudios, imagens e quaisquer outros materiais de pesquisa e ensino que estejam licenciados de maneira aberta, publicados com autorização expressa do autor ou ainda que estejam sob domínio público.

O eduCAPES permite a inclusão de materiais abertos que estejam mapeados em algum esquema de metadados. O portal utiliza a tecnologia DSpace, que suporta nativamente os padrões de metadados Dublin Core, e armazena arquivos em qualquer tipo de formato digital. O acesso aos materiais é feito de forma híbrida: pode ser feito por meio de sincronismo, remetendo a repositórios parceiros ou pela ferramenta busca, que retorna materiais hospedados no próprio portal, conforme o site do portal. A sincronia permite, por exemplo, que novos Objetos de Aprendizagem (OAs) sejam detectados nos repositórios e/ou automaticamente excluídos os que foram removidos (VASCONCELLOS et al., 2018).

Conforme pesquisa realizada no segundo semestre de 2018, no repositório eduCAPES havia, aproximadamente, 107 mil Objetos de Aprendizagem (denominados de materiais) publicados de maneira aberta, com autorização expressa do autor ou de domínio público. Para pesquisar e fazer download dos OAs disponíveis não é necessário nenhum cadastro. Há, contudo, restrições para submissão e a necessidade de cadastro no repositório. De acordo com a plataforma eduCAPES, somente participantes das universidades do sistema UAB têm permissão para submeter OAs.

No que diz respeito ao acesso aos OAs existentes, este pode ser feito de forma híbrida, na qual os OAs podem estar hospedados no próprio eduCAPES ou em repositórios de instituições parceiras. Caso esteja em repositórios parceiros, há um 
link na página de descrição dos OAs que direciona os usuários para os repositórios destas instituições. Para obter informações sobre esses objetos em repositórios parceiros, é feito um sincronismo de informações que permite a detecção automática dos OAs que foram adicionados ou removidos. Entre as instituições parceiras estão o Banco Internacional de Objetos Educacionais (BIOE) e o Instituto de Pesquisas Espaciais (INPE).

Após a publicação da Portaria CAPES no 183, de 21/10/2016, o Sistema Universidade Aberta do Brasil (UAB) passou a adotar o licenciamento aberto em todos os recursos didáticos elaborados para seus estudantes, em consonância com 0 disposto na Resolução CNE/CES ํo 01/2016, em seu art. 2º, §4ㅇ․

As instituições de educação superior, bem como os órgãos e as entidades da Administração Pública direta e indireta, que financiem ou fomentem a educação superior a distância, devem assegurar a criação, a disponibilização, o uso e a gestão de tecnologias e recursos educacionais abertos, por meio de licenças livres, que facilitem o uso, a revisão, a tradução, a adaptação, a recombinação, a distribuição e o compartilhamento gratuito pelo cidadão, resguardados os direitos autorais pertinentes.

A partir dos avanços tecnológicos, diversas informações passaram a ser facilmente encontradas na internet. Dentro desse contexto, surgiram os Recursos Educacionais Abertos (REA), que podem ser acessados e organizados gratuitamente na internet, normalmente, por meio da licença creative commons (FERREIRA; CARVALHO, 2018). Nesse cenário, podem ser disponibilizados diversos tipos de materiais: livros, apostilas, relatórios, entre outros documentos. Esses recursos constituem-se materiais para contribuir com o ensino-aprendizagem, estão em domínio público e visam a fortalecer todo processo educacional.

Atualmente, a presença maciça de entidades tecnológicas digitais vem promovendo uma imensa quantidade de dados que, com o passar do tempo, crescem de maneira desordenada na Internet. Esses dados gerados demandam meios diferenciados para gerenciá-los. Eles podem ser localizados na Internet, por meio de repositórios, proporcionando, entre outras características, a redução de custos de produção e de materiais educacionais (AUDINO; NASCIMENTO, 2010). Ademais, surgem, também, como recursos capazes de potencializar a reestruturação de práticas pedagógicas, criando novas maneiras de refletir sobre o uso da comunicação, da informação e da interação. Segundo Ostermann (2009) e Cevallos (2011), os mestrados profissionais (MP) foram criados pela Coordenação de Aperfeiçoamento de Pessoal de Nível Superior (CAPES), em 2001, que sentiu a necessidade de a pósgraduação ser em nível profissional.

Ostermann (2009) explica que a diferença entre o MP e o mestrado acadêmico (MA) é que, enquanto o MA visa formar um pesquisador, o MP qualifica para o mercado de trabalho, ou seja, tem como objetivo formar profissionais que, no futuro, saibam utilizar a pesquisa de modo a agregar valor às suas atividades. 
Os MP têm como característica a elaboração e validação de produtos técnicos. Seguindo a orientação de Moreira e Nardi (2009), o trabalho final de curso do aluno do MP na área de ensino deve ser um relato de experiência sobre uma implementação de estratégia ou produto de natureza educacional, com o objetivo de melhorar o ensino.

Nesse sentido, considerando a natureza epistemológica dos MP, o Trabalho de Conclusão Final do Curso deve procurar contribuir para a produção, apropriação e aplicação do conhecimento embasado no rigor metodológico e nos fundamentos científicos, com foco na pesquisa aplicada e na proposição de inovações e aperfeiçoamentos tecnológicos para a resolução de situações e problemas concretos (VAILANT; SOUZA, 2016; FREIRE, GUERRINI; DUTRA, 2016).

Para esse contexto, o art. $7^{\circ}$, $\S 3^{\circ}$ da Portaria Normativa CAPES n. 17, de 28 de dezembro de 2009, estabelece diferentes formatos para o Trabalho de Conclusão Final do Curso, tais como

\begin{abstract}
Dissertação, revisão sistemática e aprofundada da literatura, artigo, patente, registros de propriedade intelectual, projetos técnicos, publicações tecnológicas; desenvolvimento de aplicativos, de materiais didáticos e instrucionais e de produtos, processos e técnicas; produção de programas de mídia, editoria, composições, concertos, relatórios finais de pesquisa, softwares, estudos de caso, relatório técnico com regras de sigilo, manual de operação técnica, protocolo experimental ou de aplicação em serviços, proposta de intervenção em procedimentos clínicos ou de serviço pertinente, projeto de aplicação ou adequação tecnológica, protótipos para desenvolvimento ou produção de instrumentos, equipamentos e kits, projetos de inovação tecnológica, produção artística, sem prejuízo de outros formatos, de acordo com a natureza da área e a finalidade do curso.
\end{abstract}

A Capes (BRASIL, 2013, p. 25) descreve como deve ser o produto educacional. Este deve caracterizar-se como: "uma sequência didática, um aplicativo computacional, um jogo, um vídeo, um conjunto de videoaulas, um equipamento, uma exposição etc." É importante ressaltar que o produto gerado da dissertação deve ser, nas palavras de Moreira e Nardi (2009, p. 04), "algo identificável e independente da dissertação". Os autores alegam que, apesar de a dissertação ser sobre o produto, ele deve ter "identidade própria" e deve ser disponibilizado na página do programa para que possa ser analisado e utilizado pelos professores e profissionais de ensino formal e/ou não formal, visando sempre à melhoria na Educação Básica.

Dessa forma, o objetivo dos produtos educacionais nos MP é a inovação didática comprometida com o fortalecimento da cidadania e a inclusão social, sinalizando para a solução de problemas junto às demandas advindas da comunidade acadêmica. Há várias defesas em relação à formulação de "questões-foco" e não de questões de pesquisa para o desenvolvimento desses projetos, como explicam Ostermann e Rezende (2009): 
[...] uma questão-foco deve se relacionar a formas de se conceber, implementar e avaliar inovações didáticas (estando vinculadas a metodologias de ensino, conteúdos e avaliação); já questões de pesquisa podem se reportar a práticas educativas estudadas à luz de pressupostos sustentados por referenciais teóricos, metodológicos, epistemológicos e terem como principal objetivo orientar a produção de conhecimento científico (OSTERMANN; REZENDE, 2009, p. 72).

O Conceito de Objetos de Aprendizagem como produto educacional, relacionado com a tecnologia voltada para área de educação, pode ser entendido como componentes que podem ser usados, reusados ou referenciados durante a aprendizagem suportada pela tecnologia. $\mathrm{Na}$ área de educação, embora existam muitos materiais educacionais sendo criados e disponibilizados, o acesso a eles tornase um processo cansativo e, muitas vezes, sem sucesso.

As ferramentas de busca disponíveis concentram uma grande quantidade de informações e, às vezes, ficam muito confusas, não satisfazendo às expectativas dos usuários. Organizar e recuperar as informações científicas e tecnológicas contidas na Plataforma eduCAPES converge para a efetividade da utilização de conhecimento produzido, com vistas à qualificação do processo de ensino-aprendizagem na educação básica.

\section{O CONHECIMENTO DOS PROFESSORES DO IF BAIANO SOBRE OS RECURSOS ABERTOS (REA), SOBRE OS OSBJETOS DE APRENDIZAGEM (OAs) E SOBRE A PLATAFORMA EDUCAPES}

Ao pesquisar junto aos docentes do IF Baiano os aspectos relacionados às tecnologias educacionais, como, por exemplo, os recursos educacionais abertos disponíveis para acesso e utilização em plataformas digitais (Tabela 1), percebeu-se que a maioria, cerca de 50\%, não conhecia nenhuma das plataformas indicadas no questionário. Cumpre ressaltar que, nesta questão, os pesquisados poderiam marcar mais de uma alternativa.

Os gráficos apresentados em forma de figura que se seguem demonstram 0 grau de conhecimento ou utilização estabelecidos por seis níveis, sendo o nível 0 , para desconhecimento total e o nível 5, para conhecimento ou utilização total, e os níveis 1, 2, 3 e 4 sendo níveis intermediários, quanto mais próximo do nível cinco considera-se mais conhecimento e utilização e o inverso a mesma proporcionalidade. 
Tabela 1: Relação de Plataforma de Recursos Educacionais abertos conhecidas pelos docentes entrevistados $(\mathrm{N}=151)$

\begin{tabular}{lll}
\hline Plataformas Digitais & $\mathbf{( N = 1 5 1 )}$ & \% $^{\mathrm{a}}$ \\
\hline Casa das Ciências & 5 & 3,3 \\
Condigital & 2 & 1,3 \\
Curta na Escola & 4 & 2,6 \\
EduCAPES & 13 & 8,6 \\
Fábrica Virtual & 2 & 1,3 \\
Laboratório de Objetos de Aprendizagem - LOA (UFSCar) & 3 & 2,0 \\
Mídias Digitais para Matemática & 4 & 2,6 \\
Plataforma MEC & 32 & 21,2 \\
Portal e-Unicamp & 6 & 4,0 \\
RIVED - Rede Interativa de Educação & 2 & 1,3 \\
Teia da Vida & 3 & 2,0 \\
Nenhuma das opções & 75 & 49,7 \\
\hline
\end{tabular}

a Total não soma $100 \%$ devido às aproximações

Fonte: Dados da pesquisa

A Figura 1 aponta para um panorama em que maioria, $70 \%$ dos pesquisados, respondeu que não conhece a plataforma eduCAPES, sendo que apenas 3 docentes informaram que possuem grau de conhecimento 5 , ou seja, conhecimento total. Esta realidade ainda é distante de convergir com o caminhar contemporâneo, no qual muitas informações e produtos educacionais, fruto de pesquisas qualificadas estão disponíveis em ambientes virtuais, como por exemplo, na plataforma eduCAPES.

Figura 1: Distribuição dos respondentes pelo Grau de Conhecimento da Plataforma eduCAPES, sendo "0" para desconhecimento e " 5 " para conhecimento total

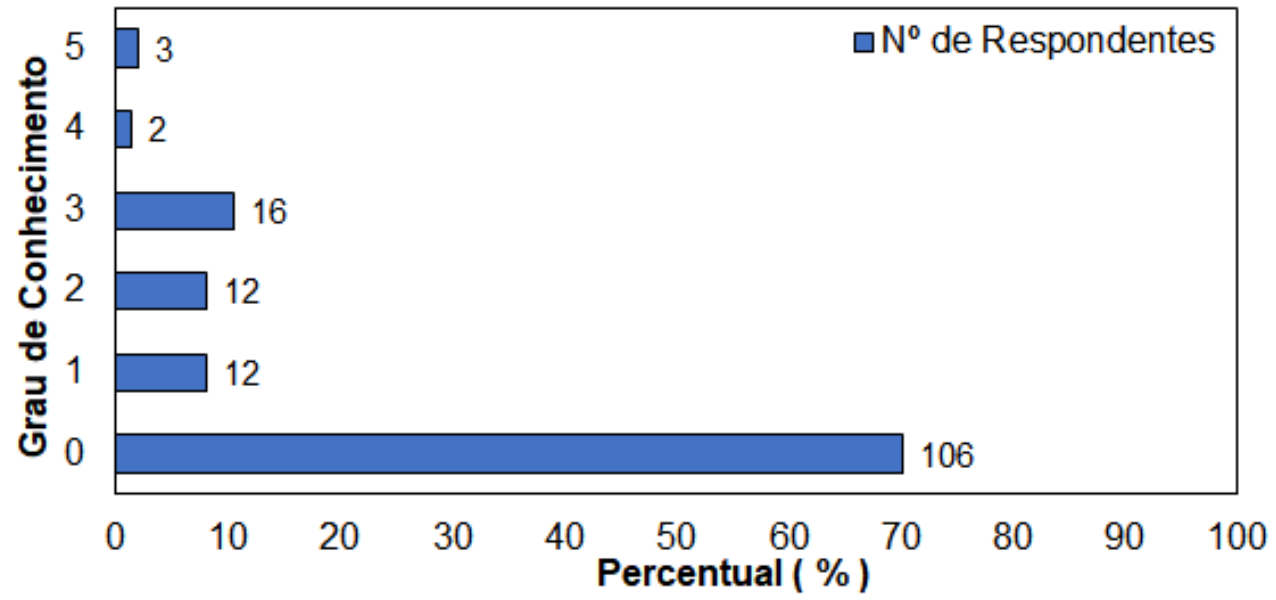

Fonte: Dados da pesquisa

Ao pesquisar o grau de conhecimentos dos docentes do IF Baiano sobre os recursos educacionais abertos, conforme a Figura 2, cerca de $80 \%$ informaram que possuem grau de conhecimento 0 , ou seja, desconhecimento total sobre o assunto. 
Figura 2: Distribuição dos respondentes pelo grau de conhecimento sobre Recurso Educacional Aberto-REA, sendo "0" para desconhecimento e "5" para conhecimento total

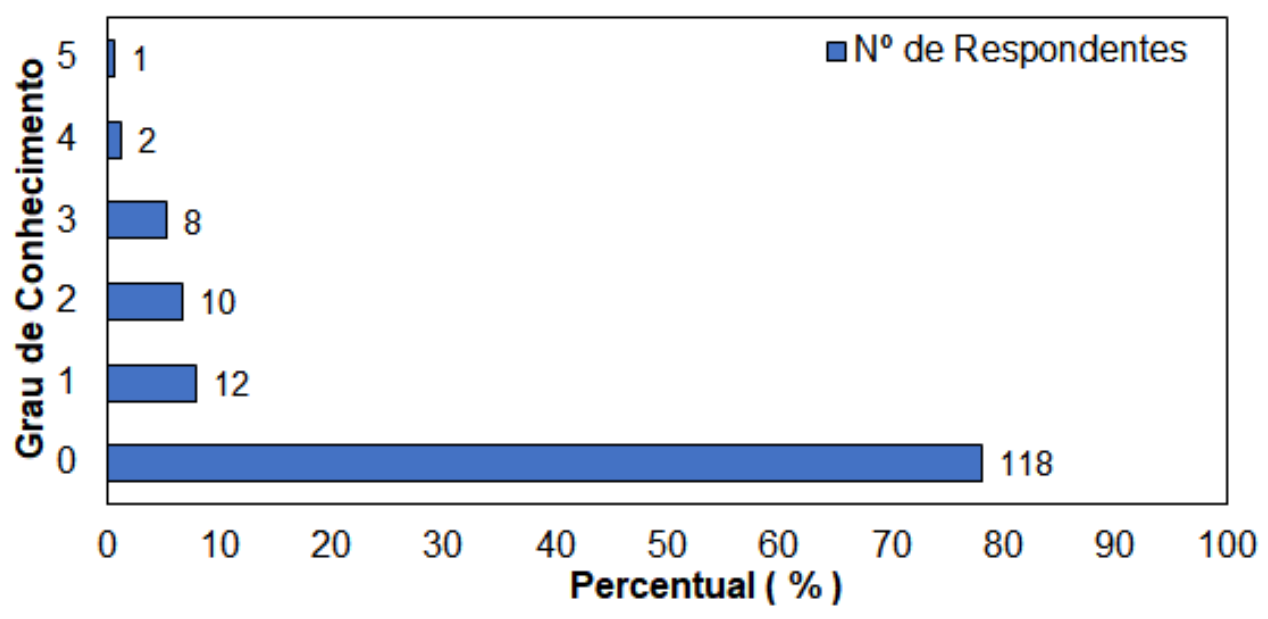

Fonte: Dados da pesquisa

A Figura 3 retrata a realidade observada no IF Baiano, em que $8,6 \%$ dos participantes da pesquisa declaram que não utilizam em sala de aula Objetos de Aprendizagem, e 13,9\% informaram que utilizam plenamente. Nesse cenário, $77,5 \%$ dos pesquisados possuem graus intermediários de utilização, remetendo à compreensão de que os Objetos de Aprendizagem estão, aos poucos, fazendo parte da dinâmica metodológica diária dos docentes.

Figura 3: Relação entre percentual de respondentes e Grau de Conhecimento sobre a utilização em sala de aula dos Objetos de Aprendizagem, na forma de mídias digitais, sendo "0" para não utilização e "5" para utilização plena

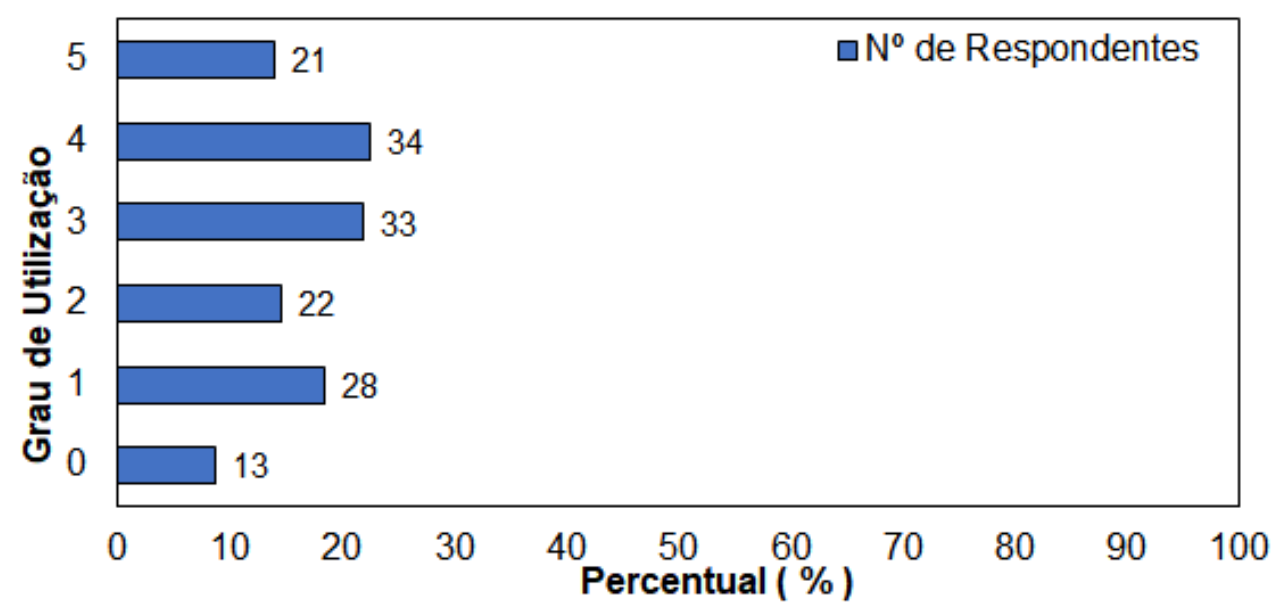

Fonte: Dados da pesquisa 
A Figura 4 nos revela o fenômeno no qual a utilização plena de OAs abertos, localizados em plataformas digitais, como suporte para o planejamento de atividades pedagógica, é muito baixa, cerca de $2,6 \%$, enquanto $37,7 \%$ declaram que não utilizam. Assim, 59,7\% informaram possuir graus intermediários de utilização.

Figura 4: Relação entre percentual de respondentes e Grau de Conhecimento sobre a utilização de plataformas digitais de Objetos Educacionais abertos como suporte para o planejamento de atividades pedagógicas, sendo "0" não utilização e "5" para

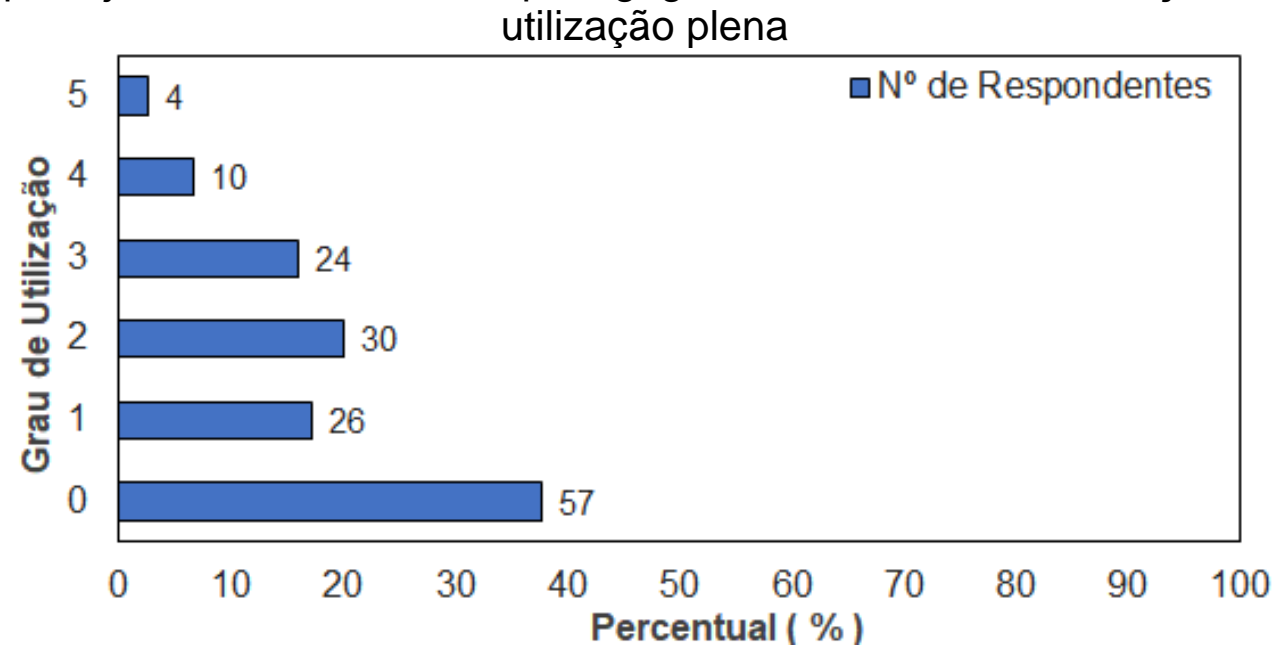

Fonte: Dados da pesquisa.

Esses dados corroboram assim a visão de Ferraz (2019), para quem

O desenvolvimento tecnológico, das últimas três décadas, tem proporcionado mudanças substanciais nos modos de circulação de Informações e nas práticas desenvolvidas em diversas esferas sociais. Tais mudanças deveriam refletir nos cenários escolares transformando as relações entre os sujeitos do processo de ensinoaprendizagem. Contudo, ainda percebemos que o ambiente escolar ainda não dialoga com o mundo permeado pelas tecnologias digitais e seus dispositivos móveis (p.119).

Pode-se dizer que a grande maioria dos professores do IF Baiano não se apropriaram da plataforma eduCAPES, tampouco dos recursos tecnológicos educacionais nela contidos. Embora este cenário revele um distanciamento destas tecnologias por parte dos professores, não se pode dizer que os docentes não manifestem interesse e disposição em utilizar estas tecnologias no processo de ensino-aprendizagem. 


\section{O USO DA PLATAFORMA EDUCAPES NA DOCÊNCIA: AS DIFICULDADES DOS PROFESSORES DO ENSINO MÉDIO INTEGRADO}

Quando se entende que a educação on-lineé um suporte ao processo que faz convergir saberes epistemológicos, didáticos e tecnológicos (TARDIF, 2006), através de uma mediação docente capacitada para atuar na web de forma crítica e provocadora, promovendo autonomia e criticidade no processo de acesso à informação e apropriação de conhecimento pelos estudantes, as plataformas digitais surgem como alternativas para fortalecer e dar suporte qualificado ao fazer profissional docente. Ao surgir, a partir da necessidade visualizada pela Diretoria de Educação à Distância - DED/CAPES - de publicizar, compartilhar e disseminar os materiais educacionais produzidos nos cursos ofertados no âmbito do Sistema Universidade Aberta do Brasil - UAB -, a Plataforma eduCapes pode contribuir com o processo de democratização do conhecimento produzido, com a autonomia dos sujeitos na busca de informações acadêmicas e, consequentemente, com o processo ensino-aprendizagem.

Quadro 1: Dificuldades e soluções acerca do uso da Plataforma eduCAPES, na percepção dos docentes do IF Baiano

\begin{tabular}{|l|l|}
\hline \multicolumn{1}{|c|}{ Dificuldades encontradas } & \multicolumn{1}{|c|}{ Soluções propostas } \\
\hline Desconhecimento & Divulgação \\
$\begin{array}{l}\text { Alegam não receber formação para } \\
\text { utilização destas tecnologias. }\end{array}$ & $\begin{array}{l}\text { Reconhecem a falta de acesso à informação } \\
\text { tecnológica e a ausência de divulgação das } \\
\text { plataformas. }\end{array}$ \\
\hline Ausência de habilidades didáticas & $\begin{array}{l}\text { Formação à luz dos pressupostos do letramento } \\
\text { informacional }\end{array}$ \\
$\begin{array}{l}\text { Percebem a importância de se conhecer } \\
\text { e utilizar ferramentas que dinamizem a } \\
\text { prática pedagógica, não só para a aula } \\
\text { em si, mas também para despertar e e } \\
\text { motivar o educando a querer conhecer e } \\
\text { a aprender. }\end{array}$ & $\begin{array}{l}\text { Compreendem a necessidade de se desenvolver } \\
\text { utilizar esses instrumentos de modo efetivo no } \\
\text { ambiente da sala de aula. }\end{array}$ \\
\hline $\begin{array}{l}\text { Infraestrutura } \\
\text { Relataram muitos problemas estruturais, } \\
\text { tais como: ausência de Internet na sala } \\
\text { de aula, falta de estrutura tecnológica na } \\
\text { instituição para apoiar o trabalho do } \\
\text { professor }\end{array}$ & $\begin{array}{l}\text { Instituir o uso de tecnologias como uma política } \\
\text { institucional, oferecendo recursos, infraestrutura e } \\
\text { apoio técnico aos professores, quando necessário. }\end{array}$ \\
\hline $\begin{array}{l}\text { Limitações da Plataforma } \\
\text { Dificuldade em encontrar material } \\
\text { disponível para download, baixo número } \\
\text { de material para disciplinas específicas, } \\
\text { como ciências agrárias. }\end{array}$ & $\begin{array}{l}\text { Publicização de pesquisas feitas sobre uso da } \\
\text { plataforma a partir de apontamentos e sugestões } \\
\text { manifestadas pelos usuários pesquisados para que } \\
\text { os gestores da plataforma conheçam as reais } \\
\text { necessidades e dificuldades encontradas para uso } \\
\text { e assim possam efetivar melhorias. }\end{array}$ \\
\hline
\end{tabular}

Fonte: Dados da pesquisa,2020 
O Quadro 1 revela, a partir da relação "desconhecimento" e "divulgação", a necessidade de promover ações relacionadas à plataforma eduCAPES de forma abrangente, objetiva e de fácil acesso e disseminação. Os participantes da pesquisa relataram também sentir necessidade da produção de materiais com alcance em larga escala para entendimento dos aspectos básicos relacionados ao uso da plataforma.

No que se refere às habilidades didáticas, destaca-se o enfoque dos participantes da pesquisa sobre a necessidade de diversificação das metodologias e dinamização da prática pedagógica para atender a uma complexa demanda gerada no dia a dia de sala de aula, especialmente no Ensino Médio Integrado, destacandose a ansiedade dos jovens em relação ao futuro, sua necessidade de se fazer ouvir e sua valorização da sociabilidade. Além das vivências próprias da juventude, o jovem está inserido em processos que questionam e promovem sua preparação para assumir o papel de adulto, tanto no plano profissional quanto no social e no familiar (BRASIL, 2013). Os fragmentos abaixo, extraídos das entrevistas dos professores, apontam para um horizonte de preocupação dos professores relacionado às novas formas de comunicação social, de interação por meio das redes sociais, da utilização massiva dos aplicativos e aparelhos móveis de comunicação:

O professor precisa entender que o conhecimento está além dos muros da escola, além de conhecer as ferramentas digitais corretas que devem ser utilizadas para o conteúdo de sala de aula, sempre com conexão (Docente 2).

Eu acho que o ponto principal é o docente querer sair da sua zona de conforto e enfrentar os novos desafios. Para além disso, o profissional dever estar antenado com essas tecnologias e saber colocá-las à disposição dos estudantes de forma bem tranquila e didática (Docente 1).

O Cap. VIII das Diretrizes Curriculares Nacional de Educação para o Ensino Médio afirma que as unidades escolares que ofertam o Ensino Médio devem considerar a "utilização de diferentes mídias como processo de dinamização dos ambientes de aprendizagem e construção de novos saberes", destarte, acredito que para o professor saber ou desenvolver o uso de tecnologias digitais como recurso de ensino-aprendizagem faz-se necessário que o mesmo compreenda que o ambiente escolar é apenas um dos espaços onde é possível adquirir conhecimento. Ele deve ser capaz de incorporar as suas funções a compreensão que enquanto professor cabe a ele oportunizar o crescimento de seus alunos de maneira horizontal, buscando construir um indivíduo mais autônomo no processo de aprender (Docente 3).

$\mathrm{Na}$ categoria Capacitação ou Letramento profissional, relacionada ao processo de ensino-aprendizagem como um processo que vincula a informação onlineao conhecimento, observou-se que foi evidenciado uma necessidade de 
desenvolvimento e implementação de ações de capacitação, treinamento, orientação, motivação para os docentes sobre uso de tecnologias no dia a dia de sala de aula, carecendo de um movimento de ruptura com práticas pedagógicas tradicionais, onde a possibilidade de intervenção na relação ensino-aprendizagem composta pelo docente e aluno deve ser pautada em uma relação afetiva, humanista e colaborativa. Para Moraes,

Aquele professor controlador, cobrador, insensível, enciclopédico, incapaz de uma interação compreensiva e colaborativa já não faz muito sentido. $\mathrm{Na}$ realidade, nossas escolas necessitam de professores capazes de organizarem ambientes agradáveis e efetivos de aprendizagem, ambientes prazerosos e implicativos, onde os alunos sintam-se acolhidos, compreendidos e nutridos no seu sentido mais amplo (MORAES, 2007, p.18).

Assim, desenvolver o letramento informacional dos docentes proporcionará a ampliação de competências e habilidades que vão permitir compreender e utilizar os recursos tecnológicos de forma ativa e crítica. Conforme podemos observar,

Não se pode negar que as tecnologias digitais trazem um novo desenho para a educação, alterando as relações sociais e as relações com o saber. Essas transformações adentram no ambiente escolar e dão início a mudanças no processo de ensino-aprendizagem. Nessa conjuntura de mudança, acredito que os professores precisam saber nortear seus alunos sobre onde e como obter conhecimentos, como tratá-los e como utilizá-los. A pesquisa e a busca são elementos muito importantes na relação dos alunos com o ambiente em que vivem e com o conhecimento que estão aprendendo. O professor tem uma enorme função nessa ação, uma vez que as práticas pedagógicas devem consentir que os alunos não apenas recebam o conhecimento, mas também o transforme, sabendo que a utilização de plataformas digitais como ferramenta de ensino-aprendizagem esbarra, na mentalidade conservadora pois muitos docentes que ainda são avessos à utilização das soluções disponíveis on-line(Docente 3).

Percebo muitos alunos conhecem e dominam mais as ferramentas digitais do que muitos professores. Sendo assim, é necessário estrutura e recursos de qualificação/ aperfeiçoamento para que o docente domine as tecnologias e que possa aplicar em sala de aula, diversificando as metodologias, com um propósito conectado com os conteúdos e o projeto pedagógico. (Docente 2).

A Instituição deve incentivar a formação continuada dos professores, através de cursos e palestras com profissionais especializados da área de metodologias ativas e TI, estimulando a ruptura com o modelo tradicional de ensino (Docente 1). 
Ao pesquisar qual a relevância da utilização da eduCAPES, ficou evidenciado nas respostas dos participantes da pesquisa que esta plataforma possibilita a ampliação de acesso aos recursos educacionais de qualidade, favorecendo a diversificação de práticas metodológicas ancoradas em inovação educacional, compartilhamento de responsabilidades e autonomia.

A utilização da plataforma $A$ eduCAPES traz vantagens para o processo de ensino. $O$ uso das tecnologias digitais no ambiente escolar, a meu ver, determinou uma implicação positiva para a aquisição de um ensino com melhores condições de aprendizagem. Isso significa que os alunos devem ser enxergados como possuidores de potencial de ação e indivíduos capazes de ampliar seus conhecimentos buscando suporte em outros ambientes, passando a ser agentes do processo educacional e não simples receptores de conhecimentos e de ideias preestabelecidas (Docente 3).

A referida plataforma propicia tanto ao docente quanto ao estudante acesso a diversos materiais de qualidade para aprofundar 0 conhecimento através de vídeo aula, módulos com conteúdos e exercícios de aprendizagem, abordando o conteúdo de maneira diversificada. Utilizar a plataforma junto com o estudante despertará, no meu ponto de vista, uma ação reflexiva diante das aulas presenciais, assim como uma autonomia ao estudante. A eduCAPES democratiza o acesso à informação (Docente 1).

Foram salientados pelos pesquisados alguns aspectos relacionados às dificuldades encontradas para uso da eduCAPES, como falta de estrutura no ambiente escolar (laboratórios e sinal de Internet), evidenciando problemas na gestão escolar, falta de investimento na área de educação e de incentivo para o desenvolvimento de práticas pedagógicas que envolvam tecnologia. Foi salientada, também, a dificuldade em manusear a plataforma, o que converge para a necessidade de introdução de formação e capacitação sobre letramento Informacional junto ao corpo docente das instituições acadêmicas, assim como de melhorias na estrutura da página on-lineda plataforma.

As dificuldades encontradas são falta de estrutura nas escolas, o que inviabiliza o acesso e consulta de materiais pelo professor e uso da plataforma pelos alunos em sala de aula. Outra dificuldade é o acesso a materiais que só estão disponíveis após o redirecionamento para outros sites, o que as vezes não acontece (Docente 2).

No caso do IF baiano faz-se necessário a implementação de mais laboratórios e salas de aulas equipadas como equipamentos que possibilitem o uso de tal ferramenta em sala de aula. Por se tratar de um campus com características rurais, ficamos impossibilitados de utilizar instrumentos como celulares e tabletes para desenvolvimento de tais atividades pela precariedade do sinal de internet (Docente 3). 
A estrutura da plataforma carece de organização melhor. Já busquei temas que apresentava o título do arquivo e não possuía conteúdo, ou buscava em algum repositório um tema e lá tinha uns 20.000 títulos misturados, e isso dificulta muito a pesquisa (Docente 1).

De acordo com pesquisas realizadas, percebemos que o Brasil encontra-se defasado em relação ao movimento de REA quando comparado no âmbito internacional, por ter poucas iniciativas com repositórios de conteúdos digitais totalmente licenciados com Creative Commons. Assim, de acordo com Santos (2011), o Instituto de Tecnologias de Informação na Educação da UNESCO (United Nations Educational scientific and cultural organization) elaborou o projeto "Open Education Resources in Brazil: State-of-the-art" para promover o movimento de REA nos países que não falam inglês, tendo o Brasil como um dos países protagonistas. Apesar dos esforços empenhados, o Brasil encontra-se, atualmente, ainda iniciando e amadurecendo nos aspectos de conhecimento e utilização dos REAs.

Por isso, alguns desafios devem ser pensados para serem superados em relação às dificuldades encontradas relacionadas ao REA, como, por exemplo: a falta de consciência acadêmica em relação às questões de licenciamento, a qualidade e 0 modelo de sustentabilidade. Essa falta de consciência pode ser minimizada ou superada com a instauração do Movimento REA de âmbito institucional, por meio de cursos para formação e orientação de professores (HYLÉN, 2012). Lupepso, Meyer e Vosgerau (2016) evidenciaram, em um trabalho sobre o tema, desconhecimento, falta de sensibilização e domínio por parte dos professores.

A partir das tecnologias digitais interativas pode-se pensar num paradigma propiciado pela organização do conhecimento em rede, como a imagem educacional aberta denominada rede colaborativa. Nesse sentido, a contribuição da educação online tem atuado na ruptura de paradigmas tradicionais em razão do grande potencial comunicacional oferecido pelas mídias interativas (SANTOS; SANTOS; ROSSINI, 2012). Contudo, entende-se que esse processo de apropriação e utilização de REA na forma de Objeto de aprendizagem, para fins de pesquisa, aprendizagem e para fins de docência, se dará de forma gradativa, considerando a formação do professor para docência on-line e o fato de que a apropriação da filosofia aberta é um desafio que se coloca na medida em que traz junto uma concepção de educação livre, autônoma e plural (SANTOS, 2002). Assim, existem muitos desafios a serem superados diariamente através de estudos e qualificação profissional.

Além disso, as mudanças socioculturais demandadas pelas tecnologias digitais nos fazem pensar sobre o papel e a importância da docência em novos espaços de interação e de aprendizagem. Numa perspectiva menos centralizadora, mais interativa e horizontal, precisamos pesquisar e utilizar práticas colaborativas que tragam fundamentos e outras metodologias nos diversos espaços e tempos de aprendizagem (SANTOS; SANTOS; ROSSINI, 2012). Estes são desafios emergentes e que necessitam ser transpostos para que haja a ruptura de paradigmas tradicionais 
e a instauração de uma educação conectada, plural e democrática, favorecendo a multiplicação de conhecimentos e inovações nos processos educacionais.

Dessa forma, a utilização de repositórios de objetos educacionais poderá prover situações de aprendizagem mais maleáveis, expandida pelas redes sociais e tornando-se cada vez mais uma atividade democrática, inovadora na produção de bens culturais. Tudo isso em convergência com o paradigma da estrutura do conhecimento em rede, em que o espaço/tempo de práticas sociais, assim instituída pelos usos dos praticantes (CERTEAU, 1999), produz e reproduz maneiras de fazer coletivamente, construindo conhecimentos, socializando culturas.

\section{CONSIDERAÇÕES FINAIS}

A pesquisa da qual este trabalho é resultante buscou indagar se os docentes da Rede Federal de Ensino Técnico e Tecnológico do IF Baiano, especialmente aqueles que atuam no Ensino Médio Integrado, conhecem e, caso conheçam, se utilizam de repositórios de produtos educacionais capazes de contribuir com seu trabalho, como também, buscou perceber quais as dificuldades encontradas para a apropriação e utilização dos recursos educacionais disponíveis em plataformas digitais pelos professores do Ensino Médio Integrado.

O processo de ensino-aprendizagem como uma ação que vincula a informação on-line ao conhecimento, demanda do docente um papel de mediador nesta relação, em que o objetivo seja promover a democratização do conhecimento, estimulando a capacidade crítica e a autonomia do estudante. Pensar a educação, nesta perspectiva, leva a considerar que a utilização de tecnologias de modo crítico nas escolas coaduna com as demandas impostas pela contemporaneidade, nas quais o cidadão precisa estar preparado para lidar com os ambientes digitais em diversas modalidades, seja para lazer, trabalho ou pesquisa.

Ademais, a complexa demanda gerada no dia a dia de sala de aula, especialmente no EMI, com interesses e necessidades singulares, diante das novas formas de comunicação social, das redes sociais, dos aplicativos e aparelhos móveis de comunicação, exige hoje do professor uma grande diversidade de práticas metodológicas que sejam capazes de atrair o estudante e facilitar o processo de transmissão da informação em construção do conhecimento, aumentando as demandas da profissão.

Nessa perspectiva, a plataforma eduCAPES se revelou como um recurso essencial neste processo, pois podem servir a diferentes estratégias, como a formação de professores e o desenvolvimento de recursos pedagógicos, no sentido que esses podem fazer parte de um plano contínuo de desenvolvimento de carreira do magistério; para permitir o compartilhamento de boas práticas e, assim, a experimentação com novas abordagens pedagógicas; para oferecer recursos extracurriculares para o estudo individual e para tutoria a preços reduzidos em relação aos materiais impressos, além de serem recursos tecnológicos digitais que podem ser 
oferecidos em diversos formatos para atender às necessidades do Ensino Médio Integrado.

Nesse sentido, os REA, em especial os Objeto de Aprendizagem, têm um grande potencial desmedido para apoiar o sucesso das ações atuais e futuras na educação brasileira. Para tanto, as instituições de ensino precisam explorar mais possibilidades de inserção e desenvolvimento de utilização dos REA e conteúdos digitais abertos. Assim, a inovação na educação poderia também ser fomentada pelos REA, contribuindo para o desenvolvimento de novas políticas nacionais que possam verdadeiramente apoiar os objetivos de aumentar a participação na educação.

Por outro lado, os altos índices de desconhecimento da plataforma eduCAPES não representam falta de interesse e disposição por parte dos docentes em conhecer e utilizar o portal. Ao se considerar a oferta do EMI de qualidade - razão de criação dos Institutos Federais - os recursos tecnológicos disponíveis em plataformas podem contribuir para 0 desenvolvimento de práticas integradoras, formação cidadã, crítica e autônoma. Em suma, a plataforma eduCAPES se mostrou como um recurso com potencial para auxiliar os docentes nesse processo, a partir de todos os objetos educacionais depositados em seu portal, com licença gratuita e aberta para todos.

\section{REFERÊNCIAS}

AUDINO, D. F.; NASCIMENTO, R. da S. Objetos de aprendizagem - diálogo entre conceitos e uma nova proposição aplicada à educação. Revista Contemporânea de Educação. Santa Catarina, v.5, n.10, p.128-148, jul/dez 2010. Disponível em: file://E:/Mestrado\%20PROFEPT/TCC/Objeto\%20de\%20Aprendizagem/objetosdeapr endizagem.pdf. Acesso em: 20 nov. 2018.

ARAÚJO, A. C.; SILVA, C. N. N. (Orgs.). Ensino Médio Integrado no Brasil: fundamentos, práticas e desafios. Brasília: Ed. IFB, 2017.

BRASIL. Conselho Nacional de Educação, Câmara de Educação Superior.

Resolução no 01 de 11 de março de 2016. Ministério da Educação, Brasília ,DF. Disponível em http://portal.mec.gov.br/docman/marco-2016-pdf/35541-res-cne-ces001-14032016-pdf/file. Acesso em 15 out. 2018.

BRASIL, CAPES. Documento de área 2013. Disponível em http://www.capes.gov.br/legislacao/53-conteudo-estatico/servicos/2340-portarias Acesso em: 21 nov. 2018.

BRASIL. Brasil. Ministério da Educação. Secretaria de Educação Básica. Secretaria de Educação Continuada, Alfabetização, Diversidade e Inclusão. Secretaria de Educação Profissional e Tecnológica. Conselho Nacional da Educação. Câmara Nacional de Educação Básica. Diretrizes Curriculares Nacionais Gerais da Educação Básica. Brasília: MEC, SEB, DICEI, 2013. Disponível em: http://portal.mec.gov.br/index.php?option=com_docman\&view=download\&alias=155 48-d-c-n-educacao-basica-nova-pdf\&ltemid=30192. Acesso em: 17 out. 2019. 
BRASIL. Portaria Normativa/MEC n 17, de 28 de dezembro de 2009. Dispõe sobre o mestrado profissional no âmbito da Fundação Coordenação de Aperfeiçoamento de Pessoal de Nível Superior - CAPES. Diário Oficial da União, Brasília, DF, 28 dez. 2009. p. 20. Disponível em: http://www.uezo.rj.gov.br/posgraduacao/docs/Portaria-MEC-N17-28-de-mbro-de-2009.pdf. Acesso em 20 de nov.2018.

CERTEAU, M. A invenção do cotidiano: artes de fazer. Petrópolis, Rio de Janeiro: Vozes, 1999.

CEVALLOS, I. O Mestrado Profissional em Ensino de Matemática e o desenvolvimento profissional de professores: um desafio institucional. 2011. 242 f. Tese (Doutorado) - Curso de Doutorado em Educação Matemática, Pontifícia Universidade Católica de São Paulo PUC/SP, São Paulo, 2011.

FERRAZ, O. (Org). Educação, (Multi)Letramentos e Tecnologias: tecendo redes de conhecimento sobre letramentos, cultura digital, ensino e aprendizagem na cibercultura. Salvador: EDUFBA, 2019.

FERREIRA, G. M. dos S.; CARVALHO, J. de S. Recursos educacionais abertos como tecnologias educacionais: considerações críticas. Debates e Polêmicas. Campinas, v. 39, n. 144, p. 738-755, set, 2018. Disponível em: file:///E:/Mestrado\%20PROFEPT/TCC/REA\%202018.pdf. Acesso em: 10 nov. 2018.

FREIRE, G. G.; GUERRINI, D.; DUTRA, A. O mestrado profissional em ensino e os produtos educacionais: a pesquisa na formação docente. Paraná: UTFPR, 2016. Disponível em:

///E:/Mestrado\%20PROFEPT/TCC/Pesquisa\%20sobre\%20Produto/2658-

Texto\%20do\%20artigo-15848-2-10-20161229.pdf. Acesso em: 20 out. 2018.

HYLÉN, J. Open Educational Resources: opportunities and challenges. OECD's Centre for Educational Research and Innovation. Retrieved March, 20, 2012, Disponível em: http://www.oecd.org/dataoecd/5/47/37351085.pdf. Acesso em: 10 mar. 2020.

LÜDKE, M.; ANDRÉ, M. E. D. A. Pesquisa em educação: abordagens qualitativas. São Paulo: EPU, 1986.

LUPEPSO, M.; MEYER, P.; VOSGERAU, D. S. A. R. Recursos educacionais abertos: potencialidades e desafios no ensino superior. Revista e-Curriculum, São Paulo, v. 14, n. 03, p. 1151-78, 2016.

MORAES, M. C. A formação do educador a partir da complexidade e da transdisciplinaridade. Diálogo Educ., Curitiba, v. 7, n. 22, p.13-38, set./dez. 2007.

MOREIRA, M. A.; NARDI, R. O mestrado profissional na área de ensino de Ciências e Matemática: Alguns esclarecimentos. Revista Brasileira de Ensino de Ciência e Tecnologia, Ponta Grossa, v. 2, n. 3, p. 1-9, 2009.

OSTERMANN, F.; REZENDE, F. Projetos de desenvolvimento e de pesquisa na área de ensino de Ciências e Matemática: uma reflexão sobre os mestrados profissionais. Caderno Brasileiro de Ensino de Física, Florianópolis, v. 26, n. 1, p.66-80, abr. 2009.

SANTOS, R. A tessitura do conhecimento via mídias digitais e redes sociais: itinerâncias de uma Pesquisa-formação multirreferencial. 2011. $232 f$. 
Dissertação (Mestrado em Educação) - Faculdade de Educação, Universidade do Estado do Rio de Janeiro, Rio de Janeiro, 2011.

SANTOS E. O currículo e o digital: educação presencial e a distância. Unpublished master dissertation, Universidade Federal da Bahia, Salvador, 2002.

SANTOS, E.; WEBER, A.; SANTOS,R. \& ROSSINI, T. Docência na cibercultura: possibilidades de usos de REA. In: Okada, A. (Ed.) Open Educational Resources and Social Networks: CoLearning and Professional Development. London: Scholio Educational Research \& Publishing, 2012. p. 1 a p. 10.

StataCorp. 2017. Stata Statistical Software: Release 15. College Station, TX: StataCorp LLC.

TARDIF, M. Saberes docentes e formação profissional. Petrópolis, Rio de Janeiro: Vozes, 2006.

VAILANT, C. C. R.; SOUZA, M. J. F. S. Características dos produtos educacionais desenvolvidos nos mestrados profissionais da região centro-oeste do Brasil. XIII Semana de licenciatura, 2016, Goiás. Anais... XIII Semana de licenciatura, Instituto Federal de Goiás, Goiás, 2016.

VASCONCELOS, I. L. B.; ARÊAS, A. B. M.; RIBEIRO, J. R. P.; OLIVEIRA, S. Castro de L.; LOPES, A. M. de A. Repositórios educacionais: uma análise da usabilidade do eduCAPES. SEER/Propesq, UFRGS, 2018. Disponível em:

file:///C:/Users/Cintia/Downloads/Referencia\%20Vasconcelos\%20Areas\%20Ribeiro \%20Olioveira\%20almeida\%20\%202018.pdf. Acesso em: 15 nov.2018. 